\title{
Relation between Hand Bone Mineral Density, Degree of Joint Destruction, and Hand Function in Adults Rheumatoid Arthritis Patients
}

\author{
Aya N. Abdelrafee, Mohamed G. E. Zaki, Abeer K. El Zohiery, and Manar A. Azab
}

\section{ABSTRACT}

Background: Rheumatoid Arthritis [RA] is a chronic systemic disease that affects the functional capacity of the hand due to inflammatory arthritis and joint destruction. RA patients have difficulties with everyday life activities and daily living activities. The prevalence of osteoporosis is estimated to be about twice that of the general population. Dual-energy Xray absorptiometry (DEXA) is the most precise tool for detecting loss in bone mineral density in RA.

Aim of the study: This study aims to investigate the relation between generalized bone mineral density (BMD) and each of hand joint destruction and hand function in order to find out its possible role in assessment of rheumatoid hand disability.

Patients and Methods: Fifty patients diagnosed as RA based on the 2010 ACR Rheumatoid Arthritis Classification Criteria were included in this study. All patients were subjected to the following scores: Duruöz Hand Index (DHI), Grip Ability Test (GAT), Grip strength test, and Pinch strength tests for assessing the function of the dominant hand of each patient. The participants were also subjected to plain $x$-ray evaluated by van der Heijde-modified total Sharp score (vdH-S) to assess the damage of the joints of the dominant hand, and Dual-energy X-ray absorptiometry (DEXA) to assess the Bone Mineral Density.

Results: The current study showed that wrist BMD was correlated with grip strength, pinch strength, GAT, and van der Heijde modified sharp score of the dominant hand. Moreover, $X$-ray joint findings were significantly correlated with each of total grip ability test, grip strength, and pinch strength as the hand disability manifested more with joint damage.

Conclusion: In conclusion, Osteoporosis, hand function, and joint damage in RA are correlated suggesting related pathophysiological mechanisms. The Severity of RA could be related to osteoporosis as well as joint destruction and hand disability.

Keywords: DEXA, hand function, Rheumatoid Arthritis [RA], van der Heijde-modified total Sharp score (vdH-S).

\section{INTRODUCTION}

Rheumatoid arthritis (RA) is a chronic systemic disease that causes pain and progressive decline of the functional capacity of the patients if not properly treated [1]. RA is the commonest of inflammatory arthritis with a prevalence rate of 1 or $2 \%$ of the population aged between 20 and 50 years worldwide [2].

The therapeutic goal is remission, a return of full function, and the maintenance of remission [3]. More than $10 \%$ of patients with RA develop deformity of small joints of the hands within the first 2 years of the disease, and at least $33 \%$ develop such deformities over time [4].

Hand function tests are important sensitive tools for the assessment of response to treatment in RA patients [5]. The upper extremity motor function tests are classified into strength tests, and hand function tests. Strength tests are grip
Published Online: July 10, 2021

ISSN: $2736-5476$

DOI: $10.24018 /$ ejclinicmed.2021.2.3.52

\section{A. N. Abdelrafee*}

National Institute of Neuromotor System, Giza, Egypt.

(e-mail: aya.nasreldin.am@ ${ }^{@ m a i l . c o m) ~}$ M. G.E. Zaki

Physical Medicine and Rehabilitation Department, Ain Shams University, Cairo, Egypt.

(e-mail: mgamalzaki50@gmail.com)

A. K. El Zohiery

Physical Medicine and Rehabilitation Department, Ain Shams University, Cairo, Egypt.

(e-mail: dr.abeerzohiery ${ }^{@}$ gmail.com) M. A. Azab Physical Medicine and Rehabilitation Department, Ain Shams University, Cairo, Egypt.

(e-mail: manarazab@yahoo.com)

*Corresponding Author strength test, and pinch strength tests while hand function tests are numerous scores can be categorized into general hand function tests and specific hand function tests for rheumatoid arthritis [6]. Hand strength in RA patients correlates with function but not with the activity of the disease [7].

Chronic inflammation due to RA disrupts the normal cycle of bone resorption and remodeling, thereby leading to osteoporosis and joint destruction [8]. The bone loss in the whole hand may be related to joint damage, principally in long-established RA [9]. Lately, imaging methods have been used to assess bone mineral density among which DXA can be considered an accurate, repeatable, and sensitive method in early RA [10]. 


\section{AIM OF THE WORK}

To study the correlation between BMD, hand joint destruction, and hand function to assess its possible role in assessment of rheumatoid hand disability.

\section{PATIENTS AND METHODS}

Fifty rheumatoid arthritis patients were recruited from Rheumatology and Physical Medicine outpatient clinics at Ain shams University hospital between December 2018 and December 2019.

Patients who were included in this study were diagnosed as rheumatoid arthritis based on the 2010 ACR/ EULAR Rheumatoid Arthritis Classification Criteria, In our study the following patients were excluded: patients with history, symptoms, and signs consistent with rheumatological disease other than rheumatoid arthritis, shoulder hand syndrome, previous hand surgery, nerve injury, fracture or dislocation of wrist and hand bones, malignancies, pregnancy and other causes of hand deformity. The exclusion was based on history, examination, laboratory tests, and radiological tests when needed.

All individuals included in this study were informed about the study design and consent was obtained. Ethical committee approval was obtained under the number: MS253, SID: 313.

All patients underwent full medical history taking with special attention to the history of pain, swelling, redness, morning stiffness, history of muscle wasting or weakness when pinching or grasping objects, and history of other joints affection.

Clinical examination was done, including general and local examination with stress on signs of joints inflammation, stability, and deformity.

Laboratory tests were done including $\mathrm{CBC}$, acute phase reactants (ESR and CRP), Rheumatoid factor (RF), and Anticyclic citrullinated peptide (Anti-CCP)

Duruöz Hand Index (DHI) was used to assess the disability in the dominant hand [11]. The total score ranges from 0 to 90, a higher score means more hand function related disability. The Duruöz Hand Index questionnaire is shown in Table I.

TABLE I: THE ARRANGEMENT OF CHANNELS

TABLE I: DURUÖZ HAND INDEX QUESTIONNAIRE [11]

\begin{tabular}{l}
\hline Answers to the questions: \\
\hline C1- in the kitchen \\
$1 \quad$ Can you hold a bowl? \\
2 Can you seize a full bottle and raise it? \\
$3 \quad$ Can you hold a plate full of food? \\
$4 \quad$ Can you pour liquid from a bottle into a glass? \\
$5 \quad$ Can you unscrew the lid from a jar opened before? \\
$6 \quad$ Can you cut meat with a knife? \\
7 Can you prick things well with a fork? \\
8 Can you peel fruit? \\
C2- Dressing \\
9 Can you button your shirt? \\
10 Can you open and close a zipper? \\
C3- Hygiene \\
11 Can you squeeze a new tube of toothpaste? \\
12 Can you hold a toothbrush efficiently? \\
C4- In the Office \\
15 Can you turn around door knob? \\
16 Can you cut a piece of paper with scissors? \\
17 Can you pick up coins from a table top? \\
18 Can you turn a key in a lock \\
Total
\end{tabular}

0: Yes, without difficulty

1: Yes, with a little difficulty

2: Yes, with some difficulty

3: Yes, with much difficulty

4: Nearly impossible to do

5: Impossible

The questionnaire was translated to Arabic language and a pilot test on few patients was performed to validate it after revision. The low-educational patients were aided by the researcher.

Grip Ability Test (GAT) is a modification of the Grip Function Test which is based on activities of daily living. The score range is 5-6 seconds to 2-3 minutes. A GAT score of $<20$ seconds is considered normal. Higher scores mean decreased hand function [12].

Grip strength is measured in pounds per square inch (PSI) by dynamometer and pinch strength is measured in pounds by pinch meter. This is done by using Baseline ${ }^{\circledR}$ Pneumatic dynamometer (30PSI).

The typical exam consists of 3-5 max effort tests with rest in between then the average is then compared to norm. We preferred to perform one single recorded attempt as the grip strength and pinch strength tests were painful for most patients with rheumatoid arthritis [13]. Patients were asked to sit comfortably with the shoulder adducted and neutrally rotated, with the elbow towards the body and flexed at 90 degrees, and the forearm and wrist are in a neutral position.

All patients were subjected to plain x-ray posteroanterior view of both hands and the joint damage in the $\mathrm{x}$-ray was assessed by Van der Heijde-modified total Sharp score (vdHS) [14]. The vdH-S identifies 16 areas of erosion and 15 areas of joint space narrowing in hand. Scoring for erosions was from 1 to 5 as Table II. Scoring Joint space narrowing was from 1 to 4 as Table III.

\begin{tabular}{|c|c|}
\hline \multicolumn{2}{|r|}{ Scoring for erosions } \\
\hline 1 & discrete erosions \\
\hline 2 & erosion reaches $25-50 \%$ of the joint surface \\
\hline 3 & erosion reaches $>50 \_75 \%$ of the joint surface \\
\hline 4 & erosion reaches $>\overline{75} \%$ of the joint surface \\
\hline 5 & bone collapses \\
\hline
\end{tabular}

TABLE III: SCORING FOR JOINT SPACE NARROWING IN VDH-S [14]

\begin{tabular}{cc}
\hline & Scoring for joint space narrowing \\
\hline 1 & focal narrowing \\
2 & generalized narrowing [ $>50 \%$ of the space left] \\
3 & $<50 \%$ of the space left or subluxation, \\
4 & complete ankylosing or luxation \\
\hline
\end{tabular}

The sum of these scores was calculated to give the total of each hand and the sum of both hands was calculated to give the total score.

Dual-energy X-ray absorptiometry was done for each patient's dominant hand, lumbar spine (L2-L4 anteroposterior view), and femur bone mineral density was measured. T-score was calculated and used in our statistical correlation. We used WHO definition for T-score as:

- Greater than or equal to -1.0: normal.

- Less than -1.0 to greater than -2.5: osteopenia.

- Less than or equal to -2.5: osteoporosis.

- Less than or equal to -2.5 plus fragility fracture: severe osteoporosis.

Data was collected and tabulated for statistical analysis. Collective and individual Dual-energy X-ray absorptiometry 
was discussed in relation to van der Heijde-modified total Sharp score and rheumatoid hand function and disability scores.

The collected data was revised, coded, tabulated, and introduced to a PC using Statistical Package for Social Science (SPSS 25). Data were presented and suitable analysis was done according to the type of data obtained for each parameter.

\section{RESULTS}

This study was conducted on 50 female adult patients with rheumatoid arthritis. Their ages ranged from 33 to 66 with mean of $50.64 \pm 8.94$ years.

As regards the dominant hand, there were 6 left-handed patients (12\%) and 44 right-handed patients (88\%). Prevalence of muscle wasting and weakness when pinching or grasping reported in history are shown in Fig. 1.

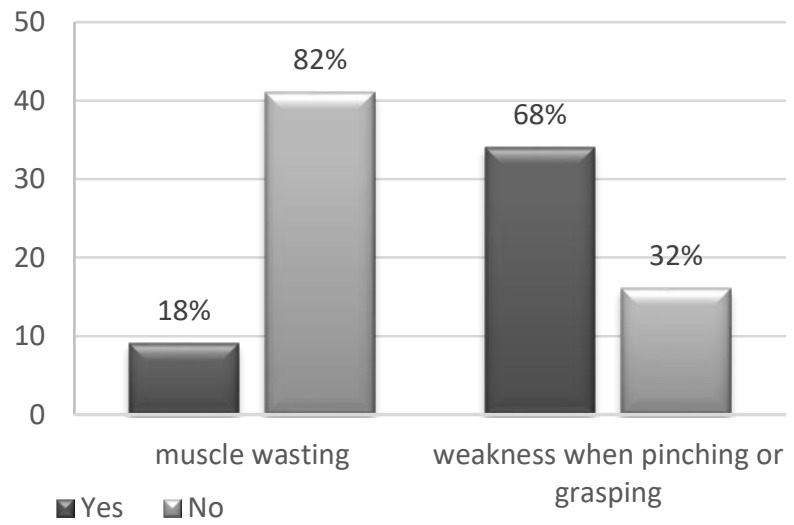

Fig. 1. Prevalence of muscle wasting and weakness when pinching or grasping reported in history.

The percentage of joint deformities among the patients in the study is shown in Fig. 2.

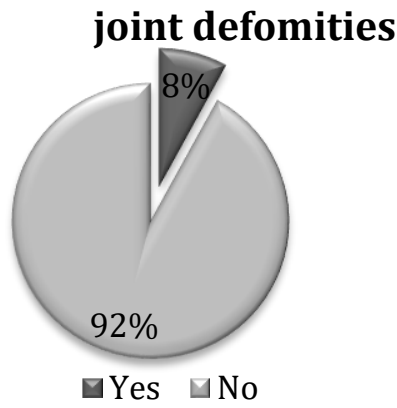

Fig. 2. Percentage of joint deformities among the patients in the study.

We graded each joint scanned by DEXA into normal, osteopenic, or osteoporotic as presented in Table IV.

The affected joints in DEXA scan of the study group are shown in Fig. 3.

The relation between wrist BMD (DEXA) and each of hand dominance, history, and hand examination] tabulated in Table V.
TABLE IV: OSTEOPOROSIS GRADE FOR THE WHOLE STUDY GROUP

\begin{tabular}{cccc}
\hline Joint & Osteoporosis grade & $\mathrm{N}$ & $\%$ \\
\hline \multirow{2}{*}{ Wrist } & Normal & 14 & $28.0 \%$ \\
& Osteopenia & 32 & $64.0 \%$ \\
& Osteoporosis & 4 & $8.0 \%$ \\
Lumbar spine & Normal & 17 & $34.0 \%$ \\
& Osteopenia & 30 & $60.0 \%$ \\
& Osteoporosis & 3 & $6.0 \%$ \\
Femur & Normal & 19 & $38.0 \%$ \\
& Osteopenia & 31 & $62.0 \%$ \\
& Osteoporosis & 0 & $0.0 \%$ \\
Most affected & Normal & 10 & $20.0 \%$ \\
joint & Wrist & 30 & $60.0 \%$ \\
& Lumbar spine & 3 & $6.0 \%$ \\
& Femur & 7 & $14.0 \%$ \\
\hline
\end{tabular}

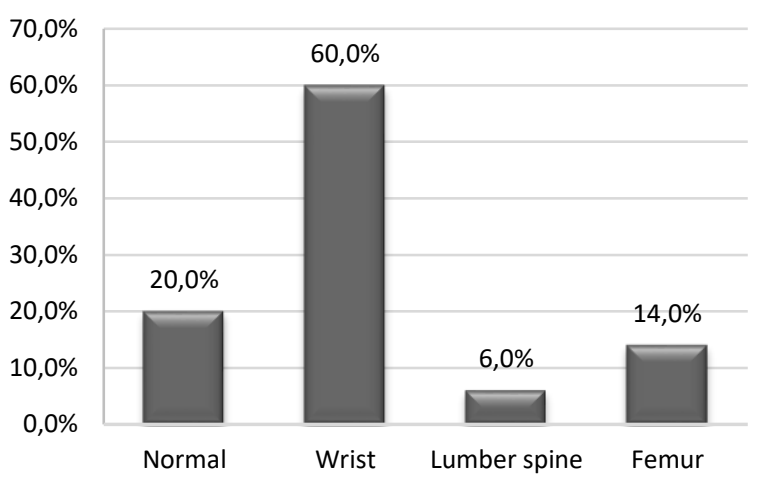

Fig. 3. the affected joint in DEXA scan of the study group.

TABLE V: RELATION BETWEEN WRIST BMD (DEXA) AND EACH OF (HAND DOMINANCE, HISTORY, AND HAND EXAMINATION)

\begin{tabular}{|c|c|c|c|c|c|}
\hline & & \multirow{2}{*}{$\begin{array}{c}\text { Wrist } \\
\text { Median [IQR] }\end{array}$} & \multicolumn{3}{|c|}{ Mann-Whitney test } \\
\hline & & & $\mathrm{U}$ & $\begin{array}{c}\text { p- } \\
\text { Value }\end{array}$ & Sig \\
\hline $\begin{array}{l}\text { Dominant } \\
\text { hand }\end{array}$ & $\begin{array}{l}\text { Right } \\
\text { Left }\end{array}$ & $\begin{array}{c}-1.5[[-2.2]-[- \\
0.9]] \\
-1.4[[-2]-[- \\
0.9]]\end{array}$ & 116 & 0.652 & NS \\
\hline $\begin{array}{l}\text { Wasting of the } \\
\text { hand muscles }\end{array}$ & Yes & $\begin{array}{c}-2.2[[-2.4]-[- \\
1.9]] \\
-1.4[[-2]-[- \\
0.8]]\end{array}$ & 92 & 0.018 & $S$ \\
\hline $\begin{array}{l}\text { Weakness } \\
\text { when pinching } \\
\text { or grasping }\end{array}$ & Yes & $\begin{array}{c}-1.65[[-2.2]- \\
[-0.9]] \\
-1.25[[-1.9]- \\
[-0.9]]\end{array}$ & 217 & 0.252 & NS \\
\hline $\begin{array}{c}\text { Joint } \\
\text { deformities }\end{array}$ & Yes & $\begin{array}{c}-1.9[[-2.85]- \\
[-1.25]] \\
-1.5[[-2.1]-[- \\
0.9]]\end{array}$ & 63 & 0.321 & NS \\
\hline
\end{tabular}

Correlation between wrist BMD and Anti CCP was calculated and shown in Fig. 4.

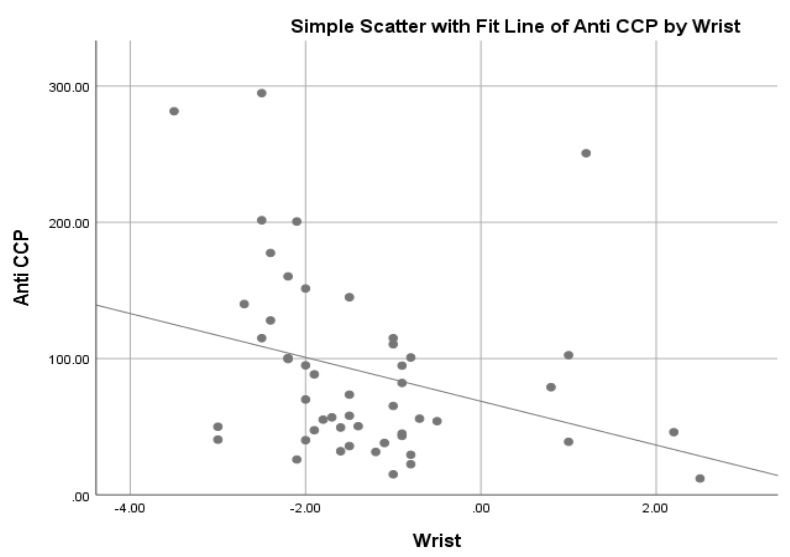

Fig. 4. Scatter with line of negative correlation between wrist BMD and Anti CCP. 
Correlation between wrist BMD (DEXA) and hand function tests (duruőz hand index (DHI), grip, and pinch strength) is shown in Table VI.
Duruőz hand index (DHI), grip strength, pinch strength] shown in Table IX.

TABLE IX: CORRELATION BETWEEN VDH-S AND GAT, DHI, GRIP STRENGTH \& PINCH STRENGTH

TABLE VI: CORRELATION BETWEEN WRIST BMD (DEXA) AND DURUÖZ HAND INDEX, GRIP, PINCH STRENGTH (TIP TO TIP PINCH STRENGTH, THREE TIP PINCH STRENGTH, AND KEY PINCH STRENGTH)

\begin{tabular}{|c|c|c|c|c|c|c|c|c|c|c|c|c|}
\hline \multicolumn{6}{|c|}{ TIP PINCH STRENGTH, AND KEY PINCH STRENGTH) } & & \multirow{2}{*}{$\begin{array}{c}\text { grip } \\
\text { ability } \\
\text { test } \\
\text { (GAT) } \\
(\mathrm{sec}) \\
\end{array}$} & \multirow{2}{*}{$\begin{array}{l}\text { Duruőz } \\
\text { hand } \\
\text { index } \\
\text { (DHI) }\end{array}$} & \multirow{2}{*}{$\begin{array}{l}\text { Grip } \\
\text { strength } \\
\text { (psi) }\end{array}$} & \multirow{2}{*}{$\begin{array}{l}\text { Tip to } \\
\text { tip pinch } \\
\text { strength } \\
\text { (PSI) }\end{array}$} & \multirow{2}{*}{$\begin{array}{l}\text { Three tip } \\
\text { pinch } \\
\text { strength } \\
\text { (PSI) }\end{array}$} & \multirow{2}{*}{$\begin{array}{c}\text { Key } \\
\text { pinch } \\
\text { strength } \\
\text { (PSI) }\end{array}$} \\
\hline & $\begin{array}{c}\text { Duruőz } \\
\text { hand } \\
\text { index } \\
\text { (DHI) }\end{array}$ & $\begin{array}{c}\text { Grip } \\
\text { strength }\end{array}$ & $\begin{array}{l}\text { Tip to } \\
\text { tip pinch } \\
\text { strength }\end{array}$ & $\begin{array}{c}\text { Three tip } \\
\text { pinch } \\
\text { strength }\end{array}$ & $\begin{array}{c}\text { Key } \\
\text { pinch } \\
\text { strength }\end{array}$ & & & & & & & \\
\hline Spearm & -0.212 & 0.492 & 0.553 & 0.429 & 0.44 & $\begin{array}{c}\text { Spearman's } \\
\text { rho }\end{array}$ & 0.418 & 0.231 & -0.548 & -0.442 & -0.441 & -0.331 \\
\hline & & & & & & $\mathrm{p}$-Value & 0.003 & 0.107 & $<0.001$ & 0.001 & 0.001 & 0.019 \\
\hline $\begin{array}{c}\mathrm{p}- \\
\mathrm{V} \mathrm{lu}_{\mathrm{u}}\end{array}$ & 0.139 & $<0.001$ & $<0.001$ & 0.002 & 0.001 & Sig. & $\mathrm{HS}$ & NS & HS & HS & HS & $\mathrm{S}$ \\
\hline
\end{tabular}

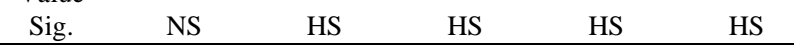

Correlation between wrist BMD (DEXA) and grip ability test was calculated and presented in Table VII.

TABLE VII: CORRELATION BETWEEN WRIST BMD (DEXA) AND GRIP ABILITY TEST (GAT)

\begin{tabular}{ccccc}
\hline & $\begin{array}{c}\text { Putting a } \\
\text { sock }\end{array}$ & $\begin{array}{c}\text { Putting a } \\
\text { paper } \\
\text { clip }\end{array}$ & $\begin{array}{c}\text { Pouring } \\
\text { water }\end{array}$ & $\begin{array}{c}\text { Total grip } \\
\text { ability test } \\
\text { (GAT) }\end{array}$ \\
\hline $\begin{array}{c}\text { Spearman's } \\
\text { rho }\end{array}$ & -0.348 & -0.307 & -0.248 & -0.362 \\
p-Value & 0.013 & 0.030 & 0.082 & 0.010 \\
Sig. & $\mathrm{S}$ & $\mathrm{S}$ & $\mathrm{NS}$ & $\mathrm{S}$ \\
\hline
\end{tabular}

Correlation between wrist BMD (DEXA) and X-ray score for joint damage (Van der Heijde modified sharp score (vdH$\mathrm{S})$ of the dominant hand) is shown in Table VIII.

TABLE VIII: CORRELATION BETWEEN WRIST BMD [DEXA] AND VAN DER HEIJDE MODIFIED SHARP SCORE (VDH-S) OF THE DOMINANT HAND

\begin{tabular}{cc} 
& $\begin{array}{c}\text { Van der Heijde modified sharp score (vdH-S) } \\
\text { of the dominant hand }\end{array}$ \\
\hline Spearman's rho & -0.673 \\
p-Value & $<0.001$ \\
Sig. & HS \\
\hline
\end{tabular}

There was statistically high significant negative correlation between wrist BMD and van der Heijde modified sharp score (vdH-S) of the dominant hand as shown in Fig. 5.

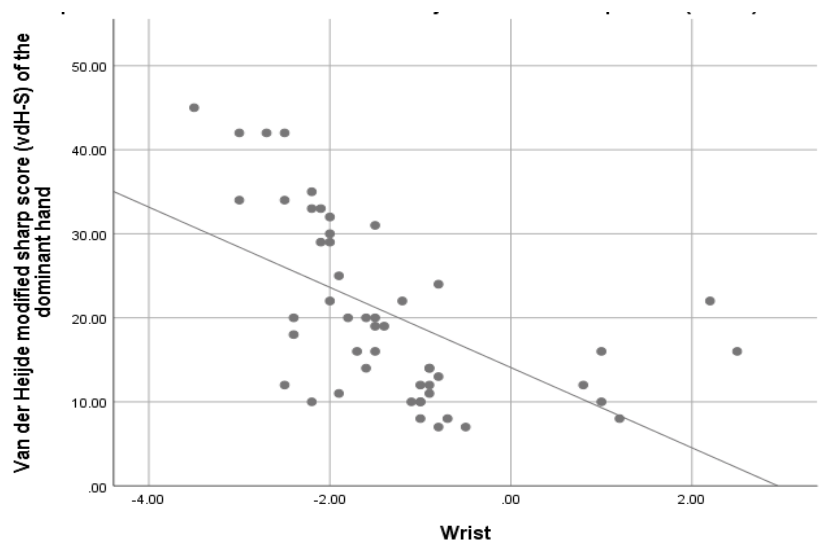

Fig 5. Scatter with line of negative correlation between wrist BMD and between van der Heijde modified sharp score (vdH-S) of the dominant hand.

The hand function tests were correlated with the joint damage of the hand proved by X-ray. Correlation between van der Heijde modified sharp score (vdH-S) of the dominant hand and the hand function tests [total grip ability (GAT),

\section{DISCUSSION}

One of the pathological hallmarks of RA is bone loss, which occurs as periarticular osteopenia or generalized osteoporosis. In RA, fibroblasts and inflammatory cells contribute to osteoclast generation, resulting in bone degradation. Physical disability caused by RA increases osteoporosis risk as well [15].

In the present study, the wrist joint was Less than -1.0 to greater than -2.5 (osteopenic) in $64 \%$ and Less than or equal to -2.5 (osteoporotic) in $8 \%$ of the patients which was a higher prevalence than that of lumbar spine and neck of femur among those patients. That came in accordance with Mochizuki et al. [9] where in his study the frequency of osteoporosis of the hand was comparatively higher than the frequency of osteoporosis of the lumbar spine and hip among their patients. Kilic and Ozgocmen [10] stated that several studies support that hand bone loss occurs more rapidly than at the hip and spine. This proves that bone loss is marked around the most affected joints characteristically small joints of the hand. Bone degradation is detected at the synovitis sites where receptor activator of nuclear factor kappa-B ligand (RANKL) is expressed [16].

In contrary to our study Hill et al. [17] observed a small reduction in hand BMD during the study period among their patients. The justification for this is due to the assessment of BMD of the non-dominant hand. In addition, Hafez et al. [18] found that the most common site of osteoporosis was the lumbar spine followed by the femur and forearm. This can be attributed to the fact that mild cases of early RA only have been enrolled in their study. The study population's characteristics, and the duration of RA, as well as age, the degree of joint involvement, and glucocorticoid therapy can all influence the rate of bone loss.

In our study wrist osteoporosis was more evident among high seropositive patients. Hafström et al. [19] also agreed that patients positive for anti-CCP had a higher frequency of reduced bone mass. Similarly, Wysham et al. [20] confirmed a negative linear relationship between anti-CCP levels and lower BMD. Accordingly, they supported the hypothesis that processes specific to RA negatively impact BMD. This suggests that higher levels of anti-citrullinated protein antibodies, stimulate greater systemic bone resorption by stimulating osteoclasts' secretion of cytokines such as interleukin (IL-8). Pro-inflammatory cytokines such as TNFa, interleukin-1 (IL-1), IL-6, IL-16, IL-17, and macrophage colony-stimulating factor (M-CSF) enhance the expression of 
RANKL. TNF-a may also have the ability to bind directly to osteoclast precursors through the TNF-a receptor and promote the formation of osteoclasts [21].

Moreover, osteoporosis was marked among our patients with more hand function disability as the hand bone mineral density was significantly positively correlated with grip strength, three tip pinch strength, tip to tip pinch strength, and key pinch strength. Yet, there was no significant correlation between hand bone mineral density and durouz hand index (DHI). This supports that muscle strength correlates to bone mineral density (BMD) and important for bone health. This relationship could be explained by the fact that stronger muscles exert more stretch on bones. This mechanical stretch on the bones can aid in the shaping of the bone structure and the increase of bone mass. Recent studies suggest that muscles may also act via cytokines, which are secreted through autocrine, paracrine, or endocrine and are referred to as myokines. Myokines affect bone metabolism in a variety of physiological and pathological ways, and they are thought to play a role in the pathogenesis of osteoporosis [22].

This was also approved by Lee and Gong [23], and Dogu et al. [24]. In the last study significant positive correlation between hand BMD and hand grip strength, as well as all pinch strength, was observed, while no statistically significant relation was observed between BMD and DHI. This was probably because DHI assesses the hand ability without considering pain or inflammation which may affect the hand function momentary more than the bone loss.

Contradicting results were detected by Deodhar et al. who mentioned in their study [25] that the percentage change in hand BMD at five years showed a significant correlation with DHI. This contradiction is probably due to correlating the DHI with the cumulative loss of hand BMD for five years in their study.

In our study, there was significant correlation between hand BMD and van der Heijde modified sharp score (vdH-S) of the dominant hand. This came in agreement with Mochizuki et al. [9] as Hand BMD is correlated with the vdH$\mathrm{S}$ in long-established RA in his study. Hill et al. [18] also found that hand BMD in RA subjects correlated with radiographic score, and the same was the study of Dogu et al. [24], Hafez et al. [18]. Although in the last study the radiological score used was different from van der Heijde. That supports the hypothesis that both joint damage and osteoporosis in RA are caused by the same pathophysiological mechanisms. The inflammatory process of RA produces RANKL which binds to receptor activator of nuclear factor-k [RANK] and activates osteoclastogenesis. OPG is a decoy receptor for RANKL. The ratio of RANKL/OPG determines the degree of osteoclast-mediated bone resorption. Lately, interest grew in the osteoblast in inflammatory arthritis. Increased bone resorption would normally be accompanied by increased bone formation by the osteoblasts, but in RA, studies indicate that inflammation can suppress the osteoblast's bone formation activity. The wingless protein (Wnt) pathway activates the osteoblast, which also contributes to the activation of Osteoprotegerin (OPG), which decreases the activity of the osteoclast. TNF- $\alpha$ appears to activate Dickkopf 1 (DKK1), which inhibits Wnt pathway. This causes both the osteoblast and the OPG to be downregulated, inhibiting bone formation. In this way, RA inflammation appears to suppress osteoblasts, resulting in a compounding effect of inflammation on bone [21].

The severity of RA is attributed to several factors such as disease duration, disease activity, Anti CCP, and RF levels. Inflammation and disease activity cause bone loss, which can aggravate systemic bone loss. The bone density of RA patients declines as local bone erosion increases, and the rate of osteoporosis rises [27]. Furthermore, disease duration, seropositivity for anti-cyclic citrullinated peptide antibody (anti-CCP), and rheumatoid factor (RF) have been shown to be associated with bone loss in RA [15]. RA patients in remission or with low disease activity are less likely to have osteoporosis as compared to patients with high disease activity [28]. This could be an indication that severity of RA could be related to each of osteoporosis, joint damage, and hand disability.

Van der Heijde modified sharp score was significantly correlated with each of total grip ability test (GAT), grip strength, and pinch strength. Indicating that hand function disability was more dominating among more damaged joints. Dogu et al. [24] also agreed that modified sharp scores were found correlated with the general disability and hand functions. Likewise, Dedeoğlu et al., 2013[29] reported that hand grip and pinch strengths were negatively correlated with articular damage in patients with RA.

On the contrary Birtane et al. [30], and Scott et al. [31] reported that radiological damage shown in hand radiographs did not correlate with hand functions, especially in early RA. The discordance between the results may be attributed to the differences in radiological assessment, disease activity, and the duration of the disease.

The main limitation of this study is its relatively small sized sample. However, this sample size could detect statistically significant correlation between our variables with $80 \%$ power.

Hence, we endorse the routine use of DEXA to assess the hand bone mineral density among RA patients to alter the therapeutic plan accordingly in order to achieve higher rates of remission. We recommend further studies comparing DEXA to Magnetic resonance imaging and ultrasound on a wider study sample. Studies on the relation between the severity of RA and osteoporosis should be considered.

\section{CONCLUSION}

In conclusion, Osteoporosis, hand function, and joint damage in RA are correlated suggesting related pathophysiological mechanisms. The severity of RA could be related to osteoporosis as well as joint destruction and hand disability.

\section{REFERENCES}

[1] Van Nies JA, Krabben A, Schoones JW, Huizinga TW, Kloppenburg M, van derHelm-van Mil AH. "What is the evidence for the presence of a therapeutic win-dow of opportunity in rheumatoid arthritis? A systematic literature reviews" AnnRheum Dis. 2014; 73:861-70.2.

[2] Akram M, Daniyal M, Sultana S, Owais A, Akhtar N, Zahid R, Said F Bouyahya A, Ponomarev E, Ali Shariat M, Thiruvengadam M. "Traditional and modern management strategies for rheumatoid arthritis" Clinica Chimica Acta; International Journal of Clinical Chemistry. 2021 Jan; 512:142-155.

[3] Smolen JS, Landewe R, Breedveld FC, et al. "EULAR 
recommendations for the management of rheumatoid arthritis with synthetic and biological disease- modifying antirheumatic drugs: 2013 update". Ann Rheum Dis. 2014; 73:492-509.

[4] Stephanie Tom, Kelley and Firestein's Textbook of Rheumatology, 2volume Set, 10th Edition, The Journal of Rheumatology, 2017, 44 (6) 964.

[5] Romero-Guzmán A.K., Menchaca-Tapia V.M., Contreras-Yáñez I., Pascual-Ramos V. "Patient and physician perspectives of hand function in a cohort of rheumatoid arthritis patients: the impact of disease activity". BMC Musculoskelet Disord, 2016: 17, 392.

[6] van Tuijl J., Janssen-Potten Y. \& Seelen H. "Evaluation of upper extremity motor function tests in tetraplegics". Spinal Cord, 2002, $40,51-64$.

[7] Sferra da Silva G., de Almeida Lourenço M. \& de Assis M.R. "Hand strength in patients with RA correlates strongly with function but not with activity of disease". Adv Rheumatol, 2018; 58: 20.

[8] $\mathrm{Xu} \mathrm{S}$, Wang Y, Lu J, Xu J. "Osteoprotegerin and RANKL in the pathogenesis of rheumatoid arthritis-induced osteoporosis". Rheumatol Int. 2012; 32: 3397-3403.

[9] Mochizuki T, Yano K, Ikari K, Hiroshima R, Sakuma Y, Momohara S. "Correlation between hand bone mineral density and joint destruction in established rheumatoid arthritis". J Orthop. 2017, 14(4):461-465.

[10] Kilic G and Ozgocmen S, "Hand bone mass in rheumatoid arthritis: A review of the literature". World J Orthop. 2015; 6(1): 106-116.

[11] Duruöz MT, Poiraudeau S, Fermanian J, et al. "Development and validation of a rheumatoid hand functional disability scale that assess functional handicap". J Rheumatol. 1996; 23:1167-72.

[12] Poole J., "Measures of Hand Function". Arthritis Care \& Research, Vol. 63, No. S11, 2011, pp S189-S199.

[13] Higgins SC, Adams J, Hughes R. "Measuring hand grip strength in rheumatoid arthritis". Rheumatol Int. 2018; 38(5):707-714.

[14] Van der Heijde D. Radiographic progression in rheumatoid arthritis: dose it reflect outcome? Dose it reflect treatment? Ann Rheum Dis. $2001 ; 60: 47-50$.

[15] Heidari B, Hassanjani Roushan MR. "Rheumatoid arthritis and osteoporosis". Caspian J Intern Med. 2012; 3(3):445-446

[16] Tanaka S, Tanaka Y. "RANKL as a therapeutic target of rheumatoid arthritis". J Bone Miner Metab. 2021 Jan; 39(1):106-112.

[17] Hill CL, Schultz CG, Wu R, Chatterton BE, Cleland LG. "Measurement of hand bone mineral density in early rheumatoid arthritis using dual energy X-ray absorptiometry". Int J Rheum Dis. 2010; 13(3):230-4.

[18] Hafez EA, Mansour HE, Hamza SH, Moftah SG, Younes TB, Ismail MA. "Bone mineral density changes in patients with recent-onset rheumatoid arthritis". Clin Med Insights Arthritis Musculoskelet Disord. 2011; 4:87-94.

[19] Hafström I., Ajeganova S., Forslind K., Svensson B., "Anticitrullinated protein antibodies are associated with osteopenia but not with pain at diagnosis of rheumatoid arthritis: data from the BARFOT cohort". Arthritis Res Ther. 2019; 21-45.

[20] Wysham KD, Shoback DM, Imboden JB Jr, Katz PP. "Association of High Anti-Cyclic Citrullinated Peptide Seropositivity and Lean Mass Index with Low Bone Mineral Density in Rheumatoid Arthritis". Arthritis Care Res (Hoboken). 2018; 70(7):961-969.

[21] Hoff M, Haugeberg G. "Using hand bone mass measurements to assess progression of rheumatoid arthritis". Ther Adv Musculoskelet Dis. 2010; 2(2):79-87.

[22] Luo Y, Jiang K, He M. "Association between grip strength and bone mineral density in general US population of NHANES 2013-2014". Arch Osteoporos. 2020 Mar 16; 15(1):47.

[23] Lee SH, Gong HS. "Measurement and Interpretation of Handgrip Strength for Research on Sarcopenia and Osteoporosis". Journal of Bone Metabolism. 2020; 27(2):85-96.

[24] Dogu B, Kuran B, Yilmaz F, Usen A, Sirzai H. "Is hand bone mineral density a marker for hand function in patients with established rheumatoid arthritis? The correlation among bone mineral density of the hand, radiological findings, and hand function". Clin Rheumatol. 2013; 32(8):1177-83.

[25] Deodhar AA, Brabyn J, Pande I, Scott DL, Woolf AD. "Hand bone densitometry in rheumatoid arthritis, a five-year longitudinal study: an outcome measure and a prognostic marker". Ann Rheum Dis. 2003; 62(8):767-770.

[26] Li YZ, Zhuang HF, Cai SQ, Lin CK, Wang PW, Yan LS, Lin JK, Yu HM. "Low Grip Strength is a Strong Risk Factor of Osteoporosis in Postmenopausal Women”. Orthop Surg. 2018; 10(1):17-22.

[27] Yamamoto Y, Turkiewicz A, Wingstrand H, Englund M. "Fragility fractures in patients with rheumatoid arthritis and osteoarthritis compared with the general population [J]". J Rheumatol. 2015 42(11):2055-2058

[28] Lindner, L., Callhoff, J., Alten, R. et al. "Osteoporosis in patients with rheumatoid arthritis: trends in the German National Database 2007 2017”. Rheumatol Int, 2020; 40, 2005-2012.

[29] Dedeoğlu M, Gafuroğlu Ü, Yilmaz Ö, Bodur H. "The relationship between hand grip and pinch strengths and disease activity, articular damage, pain, and disability in patients with rheumatoid arthritis". Turk J Rheumatol 2013; 28(2):69-77.

[30] Birtane M, Kabayel DD, Uzunca K, Unlu E, Tastekin N. "The relation of hand functions with radiological damage and disease activity in rheumatoid arthritis". Rheumatol Int. 2008; 28(5):407-12.

[31] Scott DL, Smith C, Kingsley G. "Joint damage and disability in rheumatoid arthritis: an updated systematic review". Clin Exp Rheumatol. 2003; 21(5 Suppl 31): S20-7. 